\title{
L-glutamine decreases the severity of mucositis induced by chemoradiotherapy in patients with locally advanced head and neck cancer: A double-blind, randomized, placebo-controlled trial
}

\author{
TAKAE TSUJIMOTO ${ }^{1-3}$, YOSHIFUMI YAMAMOTO $^{4}$, MASAFUMI WASA $^{5}$, YUKINORI TAKENAKA ${ }^{4}$, \\ SUSUMU NAKAHARA ${ }^{4}$, TASTUYA TAKAGI ${ }^{6}$, MAMIKO TSUGANE ${ }^{2}$, NORIYUKI HAYASHI ${ }^{1}$, \\ KAZUHISA MAEDA ${ }^{1}$, HIDENORI INOHARA ${ }^{4}$, ETSUKO UEJIMA ${ }^{2}$ and TOSHINORI ITO ${ }^{1}$
}

\begin{abstract}
${ }^{1}$ Department of Complementary and Alternative Medicine, Osaka University Graduate School of Medicine, Suita, Osaka;
${ }^{2}$ Department of Clinical Pharmacy Research and Education, Osaka University Graduate School of Pharmaceutical Sciences,

Suita, Osaka; ${ }^{3}$ Department of Clinical Pharmacy, Faculty of Pharmaceutical Sciences, Kobe Gakuin University, Kobe, Hyogo; Departments of ${ }^{4}$ Otorhinolaryngology-Head and Neck Surgery, and ${ }^{5}$ Pediatric Surgery, Osaka University

Graduate School of Medicine, Suita, Osaka; ${ }^{6}$ Department of Pharmainformatics and Pharmacometrics, Osaka University Graduate School of Pharmaceutical Sciences, Suita, Osaka, Japan
\end{abstract}

Received June 16, 2014; Accepted August 6, 2014

DOI: $10.3892 /$ or.2014.3564

\begin{abstract}
The incidence of severe mucositis in the oral cavity, pharynx and larynx is high among patients with head and neck cancer (HNC) receiving chemoradiotherapy (CRT), resulting in significant pain and impairment of quality of life. The present study investigated whether L-glutamine (glutamine) decreases the severity of mucositis in the oral cavity, pharynx and larynx induced by CRT. This double-blind, randomized, placebo-controlled trial included 40 untreated patients with squamous cell carcinoma of the nasopharynx, oropharynx, hypopharynx or larynx. Patients received 66 or 70 Gy of total radiation at the rate of $2 \mathrm{~Gy} /$ fraction daily and 5 fractions/week. Cisplatin $\left(20 \mathrm{mg} / \mathrm{m}^{2}\right)$ and docetaxel $\left(10 \mathrm{mg} / \mathrm{m}^{2}\right)$ were intravenously co-administered once a week for 6 weeks. Patients were randomized to orally receive either glutamine (group G) or placebo (group P) at a dose of $10 \mathrm{~g} 3$ times a day throughout the CRT course. Mucositis was assessed using the National Cancer Institute Common Terminology Criteria for Adverse Events version 3.0. The primary end point was mucositis severity. Mucositis developed in all patients. A maximal mucositis grade of $\mathrm{G} 4$ was observed in 0 and $25 \%$ group $\mathrm{G}$ and $\mathrm{P}$ patients, respectively, while that of G2 was observed in 10 and $0 \%$ group $\mathrm{G}$ and $\mathrm{P}$ patients, respectively $(\mathrm{p}=0.023)$. Glutamine significantly decreased the maximal mucositis grade (group $\mathrm{G}, 2.9 \pm 0.3$; group $\mathrm{P}, 3.3 \pm 0.4 ; \mathrm{p}=0.005$ )
\end{abstract}

Correspondence to: Dr Toshinori Ito, Department of Complementary and Alternative Medicine, Osaka University Graduate School of Medicine, 2-15 Yamadaoka, Suita, Osaka 565-0871, Japan E-mail: juki@cam.med.osaka-u.ac.jp

Key words: glutamine, mucositis, chemoradiotherapy, head and neck cancer, clinical trial, supportive care, adverse effect, nutrition, quality of life, pharynx, larynx and pain score at weeks 4,5 and 6 . Glutamine significantly decreased mucositis severity in the oral cavity, pharynx and larynx induced by CRT in patients with HNC.

\section{Introduction}

Chemoradiotherapy (CRT) has led to the local control of tumor growth and an improved survival rate in patients with head and neck cancer (HNC) (1). However, a high incidence of severe mucositis over a wide area of the oral cavity, pharynx and larynx is usually induced by CRT. Patients frequently become unable to consume oral medications due to severe mucositis. Therefore, physicians are sometimes compelled to decrease the chemotherapy dose or discontinue radiation, which can adversely affect treatment outcomes (2). To date, several efforts have been made for the prevention and treatment of severe mucositis, such as oral care, topical anesthetic use, antimicrobial agent use and oral rinsing; however, no standard therapy has been established (3-5).

Glutamine is the most abundant amino acid in our body. It is a primary fuel and an essential precursor of nucleotide biosynthesis in rapidly proliferating cells such as enterocytes, fibroblasts, lymphocytes and macrophages (6-9). Therefore, glutamine is classified as a conditionally essential amino acid in these cell types (10). Furthermore, glutamine serves as a glutathione synthesis substrate and exhibits antioxidant properties. When exposed to severe stress, the body fails to synthesize sufficient amounts of this amino acid, resulting in decreased plasma glutamine levels. Under these conditions, mucosal immunity is negatively affected and glutamine release from muscle tissues is decreased. Patients with advanced cancer undergoing cytotoxic therapy reportedly develop glutamine deficiency (11).

Over the last 2 decades, several studies have tested whether glutamine decreases the incidence and severity of chemo- 
therapy-, radiotherapy- or CRT-induced mucositis (12-17). However, the study design of some clinical trials was not adequate to evaluate the role of glutamine in the prevention or treatment of mucositis, thereby leading to conflicting results (14-16). The quality of these studies was insufficient since they included a small patient sample, were poorly designed and used an inadequate glutamine dose; therefore, they were unable to evaluate the effectiveness of glutamine against mucositis. In addition, all studies conducted previously observed only oral mucositis (OM). Patients with HNC receiving CRT developed mucositis not only in the oral cavity, but also in the pharynx and larynx. A double-blind, randomized, placebo-controlled trial was required to clarify this. The present study assessed whether glutamine decreases the severity of CRT-induced mucositis in patients with HNC.

\section{Materials and methods}

Patients. Participants with pathologically diagnosed, primary squamous cell carcinoma of the nasopharynx, oropharynx, hypopharynx or larynx who were scheduled to undergo CRT were included. Forty patients between 38 and 77 years of age (median, 63.5 years) were included in the present study. Of these, $85 \%$ (34/40) were males and 15\% (6/40) were females. Patients with active mouth or throat soreness before treatment, uncontrolled diabetes mellitus, or severe renal or hepatic insufficiency were excluded.

Study design. This double-blind, randomized, placebocontrolled trial was conducted in accordance with the Helsinki Declaration. The protocol and informed consent form were reviewed and approved by the Institutional Review Board of Osaka University Hospital (ID no. 09180). All patients provided written informed consent before undergoing any study-related procedures. The present study was registered with the University Hospital Medical Information Network Clinical Trials Registry (UMIN000003991).

The patients were consecutively enrolled from May 19, 2010 to June 17, 2013. An independent observer not involved in the study conduct randomly allocated eligible patients to either the glutamine group (group G) or the placebo group (group P). The assignment of patients was randomized by gender, age $(<65$ or $\geq 65$ years) and tumor location (nasopharynx/oropharynx or hypopharynx/larynx). Glutamine, which is a dietary supplement (Emmaus Medical, Inc., Torrance, CA, USA), and placebo (Matsutani Chemical Industry Co., Ltd., Suita, Osaka, Japan) were received by 20 patients each. The patients also received 66 or $70 \mathrm{~Gy}$ of total radiation at $2 \mathrm{~Gy} /$ fraction daily and 5 fractions/week. Cisplatin $\left(20 \mathrm{mg} / \mathrm{m}^{2}\right)$ and docetaxel $\left(10 \mathrm{mg} / \mathrm{m}^{2}\right)$ were intravenously co-administered once a week for 6 weeks. The patients orally consumed $10 \mathrm{~g}$ of either glutamine or placebo 3 times a day (at 7:00, 11:00 and 16:00 h) throughout the CRT course. When patients were unable to consume glutamine or placebo orally due to severe mucositis, we dissolved the agent in water and administered it via a feeding tube $30 \mathrm{~min}$ before tube feeding was started. All patients and medical staff, including physicians, nurses, pharmacists, nutrition support team (NST) members and investigators, were in compliance with the double-blind design.
The primary end point was the severity of mucositis [National Cancer Institute Common Terminology Criteria for Adverse Events version 3.0; (NCI CTCAE ver. 3.0)]. The secondary endpoints were duration and time to mucositis onset, patient-reported pain score according to a numerical rating scale (NRS), incidence and duration of opioid use, total opioid dose, incidence and duration of nutritional supplementation, and clinical data. The safety end points were the adverse effect incidence, abnormal laboratory findings and amino acid imbalance.

Clinical and nutritional support. All patients had completed dental and oral examination before treatment and were made to undergo oral care under a nurse's supervision throughout CRT. The NST assessed all patients weekly and managed their nutritional status. When patients could not manage an adequate oral diet due to severe mucositis, nutrition supplementation was provided through feeding tubes.

Data collection. Mucositis was evaluated by images of laryngoscope using NCI CTCAE ver. 3.0. Two well-trained physicians from the Department of Otorhinolaryngology assessed mucositis in the oral cavity, pharynx and larynx once a week with a naked eye and laryngoscope until patient discharge. When grades of mucositis varied from site to site, the highest grade was chosen for the analysis. Hematological and blood chemistry tests were performed at baseline, once a week during the study treatment (weeks 1-6), and after treatment (weeks 7-9) or until patient discharge, whichever occurred first. The NRS was used as a patient-reported pain scale. Patients assessed the strongest pain experienced during a day on a 0-10 scale. The primary treatment outcome was evaluated 10 weeks after the completion of treatment using computed tomography (CT), positron emission tomography/CT (PET-CT) and biopsy.

Statistical analysis. The sample size was obtained based on the following equation:

$$
\mathrm{N} \fallingdotseq 2 \cdot \mathrm{SD}^{2} \cdot\left(\mathrm{Z}_{\alpha}+\mathrm{Z}_{\beta}\right)^{2} / \Delta^{2}
$$

$\mathrm{N}$, sample size in each group; SD, standard deviation in each group; $\Delta$, minimal difference between the populations; $\left(\mathrm{Z}_{\alpha}+\mathrm{Z}_{\beta}\right)^{2}$, index of power of test.

We found the sample size of 20 was required according to above equation. All data are expressed as means \pm standard deviations.

NCI CTCAE grade and NRS scores were analyzed using the Mann-Whitney U test, and other continuous variables were analyzed using Welch's t-test. Categorical variables were analyzed using Fisher's exact test. The Kaplan-Meier method was used to analyze the time to onset of severe mucositis $(\geq G 3)$ and the curves were compared using stratified log-rank tests. The p-values were two-sided and a value of $<0.05$ was considered to indicate a statistically significant difference. All statistical analyses were performed using JMP 11 software (SAS Institute, Inc.).

\section{Results}

Patient characteristics. Fifty patients were enrolled between May 2010 and June 2013, with the last follow-up in August of 


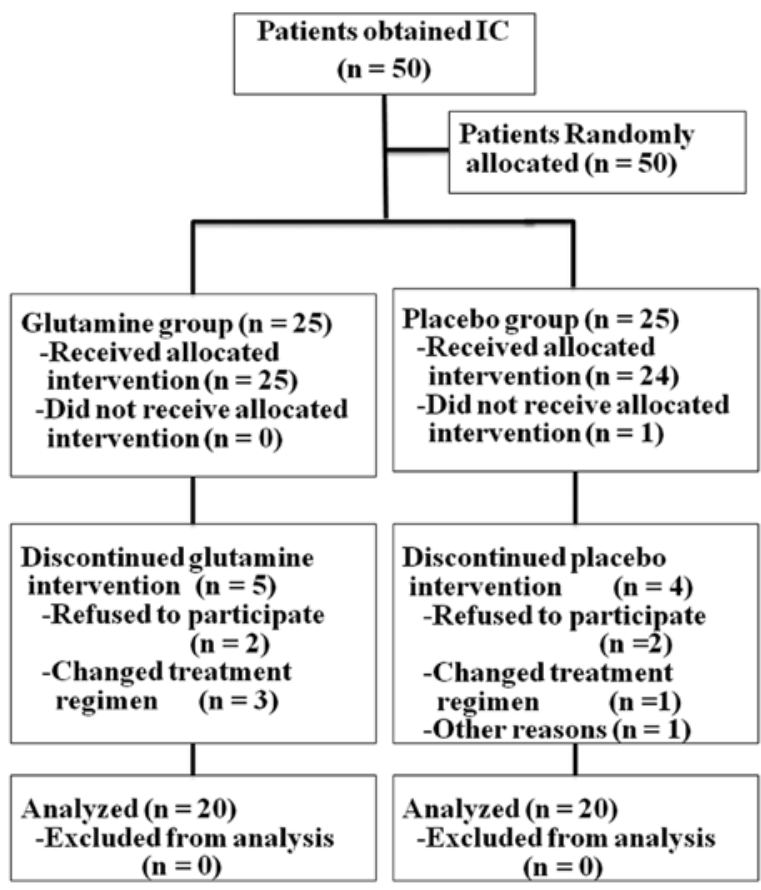

Figure 1. Consort diagram. IC, informed consent.

2013. Ten patients were excluded from analysis: 4 (group G, 3; group $\mathrm{P}, 1)$ whose treatment regimen was changed due to respiratory dysfunction or renal impairment during the CRT course, 4 (group G, 2; group P, 2) who refused to participate in the middle of the present study, and 2 (both from group P) who had to change from enteral to intravenous access. Hence, 40 patients were included in the complete analysis (Fig. 1). Baseline patient characteristics were similar between groups. There were 17 males and 3 females in each group (Table I). The average patient age was $60.5 \pm 10.8$ years in group $G$ and 63.2 \pm 5.4 years in group P. Patients in both groups were matched for primary tumor location, tumor stage, body mass index and Eastern Cooperative Group performance status. The mean total cisplatin dose was 193.3 and $187.2 \mathrm{mg}$ and the mean total docetaxel dose was 97.7 and $93.9 \mathrm{mg}$ in groups $\mathrm{G}$ and $P$, respectively. The mean total radiation dose was 66.4 and 66.2 Gy in groups $\mathrm{G}$ and $\mathrm{P}$, respectively. The oral mucosa at baseline was healthy in all patients.

Incidence and severity of mucositis. Mucositis developed in all patients in both groups. A maximal mucositis grade of G4 was observed in 0 and $25 \%$ group $\mathrm{G}$ and $\mathrm{P}$ patients, respectively, while that of $\mathrm{G} 2$ was observed in 10 and $0 \%$ group $\mathrm{G}$ and $P$ patients, respectively. Glutamine significantly decreased the mean maximal grade (group G, 2.9 \pm 0.3 ; group P, 3.3 \pm 0.4 ; $\mathrm{p}=0.005$; Table II). The mean time to mucositis onset was $2.3 \pm 0.8$ and $2.1 \pm 0.8$ weeks $(\mathrm{p}=0.663)$, while the mean mucositis duration was $4.8 \pm 0.9$ and $5.0 \pm 0.8$ weeks in groups $G$ and $P$, respectively $(\mathrm{p}=0.617)$. The mean time to severe mucositis onset $(\geq \mathrm{G} 3)$ was $4.2 \pm 1.1$ and $4.2 \pm 1.0$ weeks $(\mathrm{p}=0.829)$, while the mean severe mucositis $(\geq \mathrm{G} 3$ ) duration was $2.2 \pm 1.4$ and 2.8 \pm 1.1 weeks in groups $\mathrm{G}$ and $\mathrm{P}$, respectively (Fig. 2). The mean mucositis grade as assessed by experienced physicians was significantly lower in group $\mathrm{G}$ than in group $\mathrm{P}$ at weeks 5 and 6 ( $\mathrm{p}=0.027, \mathrm{p}=0.002$, respectively; Fig. $3 \mathrm{~A})$.
Table I. Patient characteristics.

\begin{tabular}{|c|c|c|c|}
\hline & $\begin{array}{l}\text { Glutamine } \\
\text { group } \\
(\mathrm{n}=20)\end{array}$ & $\begin{array}{l}\text { Placebo } \\
\text { group } \\
(n=20)\end{array}$ & P-value \\
\hline Male/female & $17 / 3$ & $17 / 3$ & 1 \\
\hline Age (years) & $60.5 \pm 10.8$ & $63.2 \pm 5.4$ & 0.3330 \\
\hline \multicolumn{4}{|l|}{ Primary tumor location } \\
\hline Nasopharynx & $0(0 \%)$ & $2(10 \%)$ & \multirow[t]{4}{*}{0.3755} \\
\hline Oropharynx & $10(50 \%)$ & $6(30 \%)$ & \\
\hline Hypopharynx & $7(35 \%)$ & $7(35 \%)$ & \\
\hline Larynx & $3(15 \%)$ & $5(25 \%)$ & \\
\hline \multicolumn{3}{|l|}{ Stage } & \multirow[t]{5}{*}{1} \\
\hline I & $0(0 \%)$ & $0(0 \%)$ & \\
\hline II & $2(10 \%)$ & $3(15 \%)$ & \\
\hline III & $4(20 \%)$ & $3(15 \%)$ & \\
\hline IV & $14(70 \%)$ & $14(70 \%)$ & \\
\hline \multicolumn{4}{|l|}{$\begin{array}{l}\text { ECOG performance } \\
\text { status }\end{array}$} \\
\hline 0 & $17(85 \%)$ & $19(95 \%)$ & \multirow[t]{2}{*}{0.6050} \\
\hline 1 & $3(15 \%)$ & $1(5 \%)$ & \\
\hline \multicolumn{3}{|l|}{ Total dose of radiation } & \multirow[t]{3}{*}{1} \\
\hline $66 \mathrm{~Gy}$ & $18(90 \%)$ & $19(95 \%)$ & \\
\hline 70 Gy & $2(10 \%)$ & $1(5 \%)$ & \\
\hline \multicolumn{4}{|l|}{$\begin{array}{l}\text { Total dose of chemo- } \\
\text { therapeutic agents (mg) }\end{array}$} \\
\hline Cisplatin & $193.3 \pm 19.2$ & $187.2 \pm 21.3$ & 0.3573 \\
\hline Docetaxel & $97.7 \pm 8.8$ & $93.9 \pm 10.5$ & 0.2297 \\
\hline Diabetes mellitus & $1(5 \%)$ & $3(15 \%)$ & 0.6050 \\
\hline $\begin{array}{l}\text { Body mass index } \\
\left(\mathrm{kg} / \mathrm{m}^{2}\right)\end{array}$ & $21.6 \pm 3.2$ & $22.1 \pm 3.9$ & 0.4282 \\
\hline $\begin{array}{l}\text { Daily intake of calories } \\
\text { (kcal/day) }\end{array}$ & $1,417 \pm 198$ & $1,397 \pm 232$ & 0.7709 \\
\hline
\end{tabular}

Gy, grays; ECOG, Eastern Cooperative Oncology Group. Values of age, total dose of chemotherapeutic agents, body mass index are means \pm SD and analyzed by Welch's t-test. Values of gender, primary tumor location, stage, total dose of radiation, diabetes are patient number and percentage and were analyzed by Fisher's exact test.

NRS scores and rate of opioid usage. NRS scores were significantly lower in group $\mathrm{G}$ than in group $\mathrm{P}$ at weeks 4,5 and 6 ( $\mathrm{p}=0.049, \mathrm{p}=0.019, \mathrm{p}=0.032$, respectively; Fig. 3B). In total, 17 $(85 \%)$ and 19 patients $(95 \%)$ used an opioid analgesic in addition to a non-steroidal anti-inflammatory drug (NSAID) in groups $G$ and $P$, respectively. The mean duration of opioid use was significantly shorter in group $\mathrm{G}$ than in group $\mathrm{P}$ (group $\mathrm{G}$, $19 \pm 11$ days; group $P, 28 \pm 14$ days; $p=0.029)$. The mean total opioid dose (in morphine equivalents) was $2,370 \pm 2,237 \mathrm{mg}$ in group $\mathrm{G}$ and 3,959 $\pm 3,566 \mathrm{mg}$ in group $\mathrm{P}$ ( $\mathrm{p}=0.101$; Table III).

Requirement and duration of nutritional support. Supplemental nutrition through a nasogastric tube, gastric fistula or intravenous peripheral parenteral nutrition was admin- 
Table II. Incidence and severity of mucositis.

\begin{tabular}{lcccc}
\hline & $\begin{array}{c}\text { Glutamine } \\
(\mathrm{n}=20)\end{array}$ & $\begin{array}{c}\text { Placebo } \\
(\mathrm{n}=20)\end{array}$ & P-value & $\begin{array}{c}\text { Effect } \\
\text { size }\end{array}$ \\
\hline $\begin{array}{l}\text { Incidence of } \\
\text { mucositis }\end{array}$ & $20(100 \%)$ & $20(100 \%)$ & 1 & \\
$\begin{array}{l}\text { Maximum grade } \\
\text { of mucositis }\end{array}$ & & & & \\
$\quad$ None & 0 & 0 & & \\
Grade 1 & 0 & 0 & & \\
Grade 2 & 2 & 0 & & \\
Grade 3 & 18 & 15 & & \\
Grade 4 & 0 & 5 & & \\
$\begin{array}{l}\text { Average grade } \\
\text { of mucositis }\end{array}$ & $2.9 \pm 0.3$ & $3.3 \pm 0.4$ & $0.0044^{\mathrm{b}}$ & 0.89 \\
\hline
\end{tabular}

Continuous variables were analyzed by Mann-Whitney $U$ test and categorical variables were analyzed by Fisher's exact test. ${ }^{\mathrm{a}} \mathrm{p}<0.05$, ${ }^{\mathrm{b}} \mathrm{p}<0.01$ vs. group $\mathrm{P}$.

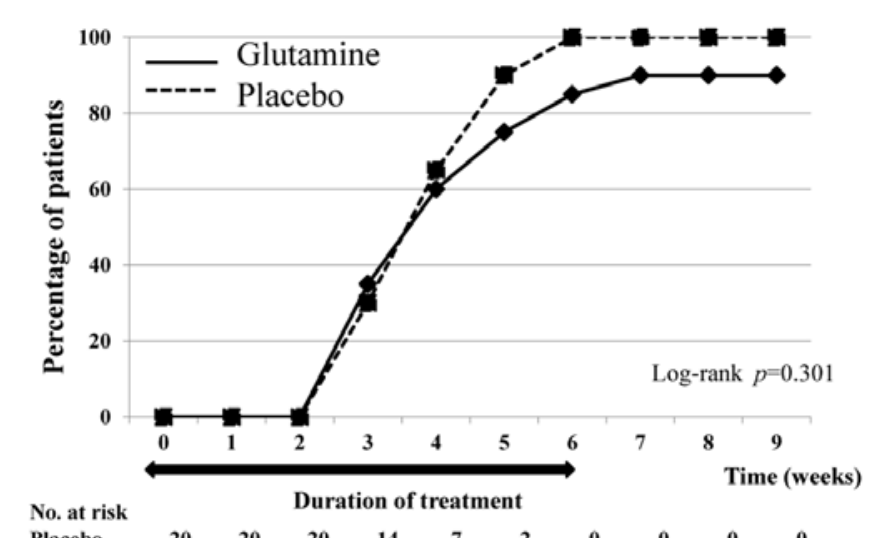

$\begin{array}{lllllllllll}\text { Placebo } & \mathbf{2 0} & \mathbf{2 0} & \mathbf{2 0} & \mathbf{1 4} & \mathbf{7} & \mathbf{2} & \mathbf{0} & \mathbf{0} & \mathbf{0} & \mathbf{0} \\ \text { Glutamine } & \mathbf{2 0} & \mathbf{2 0} & \mathbf{2 0} & \mathbf{1 3} & \mathbf{8} & \mathbf{5} & \mathbf{3} & \mathbf{2} & \mathbf{2} & \mathbf{2}\end{array}$

Figure 2. Cumulative incidence rate of severe oral mucositis. Kaplan-Meier method was used to analyze the time to onset of severe mucositis $(\geq \mathrm{G} 3$, NCI CTCAE ver. 3.0) and the curves were compared using stratified log-rank tests. NCI CTCAE ver. 3.0, National Cancer Institute Common Terminology Criteria for Adverse Events version 3.0.

istered to $16(80 \%)$ and 19 patients $(95 \%)$ in groups $\mathrm{G}$ and $\mathrm{P}$, respectively. The mean duration of supplemental nutrition required due to severe mucositis was significantly shorter in group $\mathrm{G}$ than in group $\mathrm{P}$ (group $\mathrm{G}, 18 \pm 13$; group $\mathrm{P}, 27 \pm 11$; $\mathrm{p}=0.046$; Table III). The mean percentage change in body weight from baseline to week 8 was 3.6 and $6.0 \%$ in groups $G$ and $\mathrm{P}$, respectively. Changes in average BMI were similar between groups $(21.6 \pm 3.2$ at baseline and $20.2 \pm 2.9$ at week 8 in group $G$ and $22.1 \pm 3.9$ at baseline and $20.7 \pm 3.2$ at week 8 in group P). The mean daily intake of calories was $1,417 \pm 198$ and $1,397 \pm 232 \mathrm{kcal}$ in groups $\mathrm{G}$ and $\mathrm{P}$, respectively $(\mathrm{p}=0.771$; Table I).

Biochemical blood analyses. The results of hematological and biochemical blood tests for renal function, liver function, lipids, C-reactive protein, rapid turnover protein and trace elements were comparable between groups (Table IV).
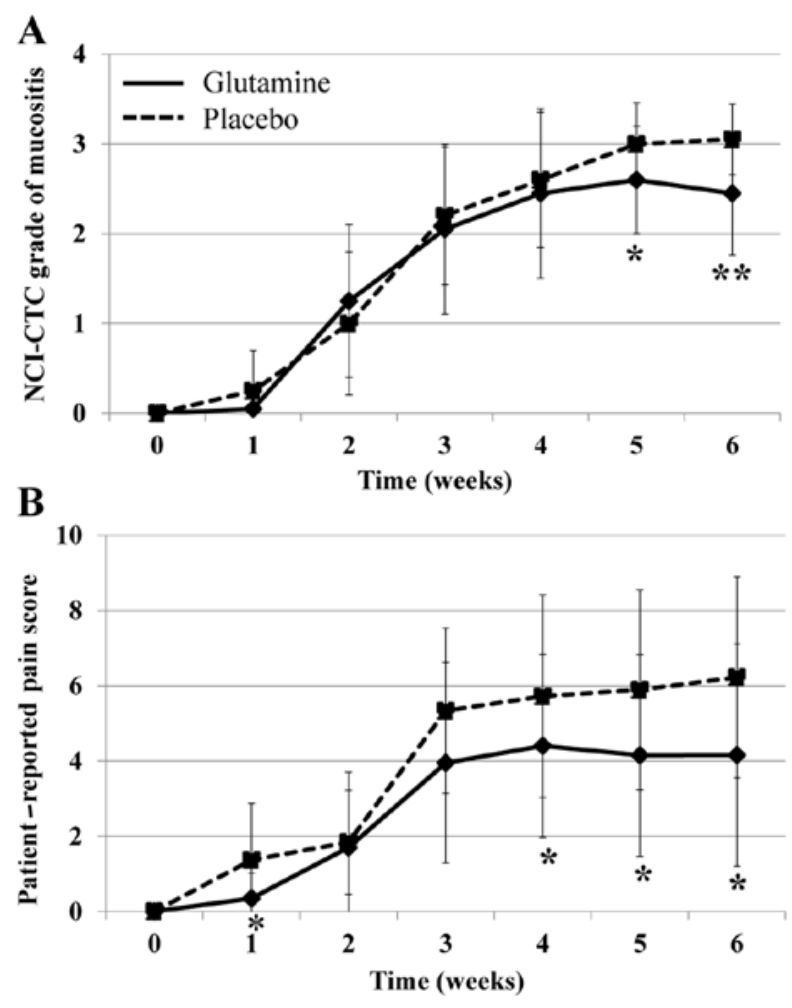

Figure 3. (A) Mean NCI CTCAE grade of mucositis. The NCI CTCAE grades were determined by two well-trained physicians weekly throughout CRT. (B) Mean patient-reported pain score. NRS was used as a patient-reported pain score. Patients assessed the strongest pain experienced during a day on a 0-10 scale. Both NCI CTCAE grades and NRS scores were analyzed using Mann-Whitney U test. ${ }^{*} \mathrm{p}<0.05 ;{ }^{*} \mathrm{p}<0.01$ vs. group P. NCI CTCAE, National Cancer Institute Common Terminology Criteria for Adverse Events; NRS, numerical rating scale.

Adverse effects of CRT. Severe mucositis interrupted CRT in 3 patients $(15 \%)$ in group $P$ but no patient in group $G$. There were no adverse effects and abnormal laboratory findings in group G. The amino acid profiles showed that glutamine did not affect the overall amino acid balance (data not shown).

Influence of glutamine on the primary treatment outcome. After 10 weeks of treatment, tumor response was evaluated using PET-CT and histopathological examination of biopsy specimens. The tumor responses in group $\mathrm{G}$ were as follows: complete response (CR), 65\%, 13/20; partial response (PR), 25\%, 5/20; stable disease (SD), 10\%, 2/20; and progressive disease (PD), 0\%, 0/20. Those in group P were as follows: CR, $60 \%, 12 / 20$; PR, 25\%, 5/20; SD, 0\%, 0/20; PD, 10\%, 2/20; and unknown, $5 \%, 1 / 20$. The response rate was $90 \%$ in group $\mathrm{G}$ and $85 \%$ in group $\mathrm{P}$.

\section{Discussion}

The present study demonstrated that glutamine significantly decreased the severity of CRT-induced mucositis in patients with HNC. Glutamine has important and unique metabolic properties. Free and abundant glutamine in the circulation as well as intracellular pools is essential for DNA synthesis, cell division and cell growth, all of which are necessary for wound healing and tissue repair (18). Glutamine participates in protein 
Table III. Incidence of opioid use and supplemental nutrition due to mucositis.

\begin{tabular}{lccc}
\hline & Glutamine (n=20) & Placebo (n=20) & P-value \\
\hline Incidence of opioid use & $17(85 \%)$ & $19(95 \%)$ & 0.6050 \\
Time to onset of opioid use (days) & $24 \pm 9$ & $19 \pm 9$ & 0.1011 \\
Duration of opioid use (days) & $19 \pm 11$ & $28 \pm 14$ & $0.0294^{\mathrm{a}}$ \\
Total dose of opioids (mg), morphine equivalents & $2,370 \pm 2,237$ & $3,959 \pm 3,566$ & 0.1012 \\
Incidence of supplemental nutrition & $16(80 \%)$ & $19(95 \%)$ & 0.3616 \\
Time to onset of administration of supplemental & $24 \pm 11$ & $21 \pm 8$ & 0.69 \\
nutrition (days) & $18 \pm 13$ & $27 \pm 11$ & 0.52 \\
Duration of supplemental nutrition (days) & & $0.0455^{\mathrm{a}}$ & 0.35 \\
\hline
\end{tabular}

Continuous variables were analyzed by Welch's t-test and categorical variables were analyzed by Fisher's exact test. ${ }^{\mathrm{a}} \mathrm{p}<0.05$ vs. group P.

Table IV. Biochemical data of glutamine and placebo group.

\begin{tabular}{|c|c|c|c|c|}
\hline & \multicolumn{2}{|c|}{ Baseline } & \multicolumn{2}{|c|}{ After treatment } \\
\hline & $\begin{array}{l}\text { Glutamine group } \\
\qquad(\mathrm{n}=20)\end{array}$ & $\begin{array}{l}\text { Placebo group } \\
\qquad(\mathrm{n}=20)\end{array}$ & $\begin{array}{l}\text { Glutamine group } \\
\qquad(\mathrm{n}=20)\end{array}$ & $\begin{array}{l}\text { Placebo group } \\
\qquad(\mathrm{n}=20)\end{array}$ \\
\hline White blood cell count $\left(\times 10^{3} / \mathrm{mm}^{3}\right)$ & $6.2 \pm 1.5$ & $5.8 \pm 1.3$ & $3.8 \pm 1.6$ & $4.2 \pm 2.0$ \\
\hline Total neutrophil count $\left(\times 10^{3} / \mathrm{mm}^{3}\right)$ & $4,075 \pm 1,170$ & $3,689 \pm 1,211$ & $2,805 \pm 1,459$ & $3,157 \pm 2,095$ \\
\hline Total lymphocyte count $\left(\times 10^{3} / \mathrm{mm}^{3}\right)$ & $1,360 \pm 481$ & $1,430 \pm 312$ & $424 \pm 171$ & $520 \pm 204$ \\
\hline Red blood cell count $\left(\times 10^{6} / \mathrm{mm}^{3}\right)$ & $4.2 \pm 0.5$ & $4.1 \pm 0.5$ & $3.4 \pm 0.5$ & $3.3 \pm 0.3$ \\
\hline Hemoglobin, g/dl & $13.2 \pm 1.7$ & $13.1 \pm 1.7$ & $10.1 \pm 0.5$ & $10.7 \pm 1.0$ \\
\hline Platelet count $\left(\times 10^{3} / \mathrm{mm}^{3}\right)$ & $220.3 \pm 77.3$ & $248.4 \pm 83.3$ & $250.1 \pm 63.4$ & $261.3 \pm 105.0$ \\
\hline Blood urea nitrogen, $\mathrm{mg} / \mathrm{dl}$ & $14.0 \pm 4.8$ & $13.8 \pm 3.1$ & $19.0 \pm 9.8$ & $18.7 \pm 6.3$ \\
\hline Creatinine, $\mathrm{mg} / \mathrm{dl}$ & $0.7 \pm 0.2$ & $0.7 \pm 0.2$ & $0.8 \pm 0.2$ & $0.8 \pm 0.2$ \\
\hline Asparatate aminotransferase, U/1 & $24 \pm 18$ & $26 \pm 16$ & $17 \pm 5$ & $19 \pm 5$ \\
\hline Alanine aminotransferase, $\mathrm{U} / \mathrm{l}$ & $25 \pm 28$ & $19 \pm 9$ & $16 \pm 5$ & $16 \pm 5$ \\
\hline$\gamma$-glutamyl transpeptidase, $\mathrm{U} / \mathrm{l}$ & $64 \pm 87$ & $44 \pm 36$ & $48 \pm 40$ & $63 \pm 63$ \\
\hline Cholinesterase, U/1 & $282 \pm 90$ & $273 \pm 74$ & $256 \pm 83$ & $244 \pm 91$ \\
\hline Creatine phosphokinase, U/1 & $59 \pm 17$ & $64 \pm 21$ & $72 \pm 58$ & $52 \pm 31$ \\
\hline Total cholesterol, mg/dl & $182 \pm 28$ & $170 \pm 45$ & $159 \pm 23$ & $153 \pm 33$ \\
\hline Total bilirubin, mg/dl & $0.7 \pm 0.3$ & $0.6 \pm 0.1$ & $0.3 \pm 0.1$ & $0.4 \pm 0.1$ \\
\hline C-reactive protein, $\mathrm{mg} / \mathrm{dl}$ & $0.5 \pm 0.6$ & $0.5 \pm 0.6$ & $2.3 \pm 2.2$ & $2.8 \pm 3.1$ \\
\hline Albumin, $\mathrm{g} / \mathrm{dl}$ & $3.8 \pm 0.4$ & $3.7 \pm 0.4$ & $3.3 \pm 0.4$ & $3.1 \pm 0.6$ \\
\hline Transferrin, mg/dl & $222 \pm 26^{\mathrm{a}}$ & $194 \pm 28$ & $203 \pm 25$ & $172 \pm 26$ \\
\hline Transthyretin, mg/dl & $26 \pm 8$ & $22 \pm 7$ & $19 \pm 4$ & $17 \pm 8$ \\
\hline Retinol-binding protein, $\mathrm{mg} / \mathrm{dl}$ & $4.1 \pm 1.3^{\mathrm{a}}$ & $3.2 \pm 1.0$ & $3.4 \pm 0.9$ & $3.1 \pm 1.4$ \\
\hline Iron, $\mu \mathrm{g} / \mathrm{dl}$ & $85 \pm 41$ & $77 \pm 31$ & $67 \pm 29$ & $69 \pm 21$ \\
\hline Copper, $\mu \mathrm{g} / \mathrm{dl}$ & $119 \pm 25$ & $124 \pm 25$ & $143 \pm 46$ & $149 \pm 24$ \\
\hline Zinc, $\mu \mathrm{g} / \mathrm{dl}$ & $81 \pm 18$ & $75 \pm 8$ & $76 \pm 14$ & $82 \pm 17$ \\
\hline
\end{tabular}

Values are means \pm SD. ${ }^{\mathrm{a}} \mathrm{p}<0.05 \mathrm{vs}$. baseline of placebo group analyzed by Welch's t-test.

synthesis and extracellular matrix formation. Some studies have shown that glutamine increases collagen synthesis in human fibroblasts by a direct stimulatory effect and as a proline and hydroxyproline residue precursor $(19,20)$. It also enhances the immune system and is an important fuel for both macrophages and lymphocytes. Intravenous glutamine supplementation reportedly increased IgA production in rats (21). Furthermore, glutamine has antioxidant properties as a glutathione precursor. Leitao et al showed that glutamine or alanyl glutamine accelerated mucosal remodeling from 5-fluorouracil-induced OM 
by increasing glutathione stores in hamster mucosa (22). Nose et al demonstrated that bolus enteral glutamine prevented cisplatin-induced intestinal mucosal injury in rats, possibly resulting in increased intracellular glutathione (23). Several clinical studies have shown the protective effects of glutamine on the mucosal epithelium (24-26). Topkan et al reported that oral glutamine decreased the incidence and duration of acute radiation-induced esophagitis in non-small cell lung cancer patients treated with radiotherapy (24). Cerchietti et al demonstrated that intravenous L-alanyl-L-glutamine significantly decreased the severity of CRT-induced OM in patients with HNC (25). Intravenous L-alanyl-L-glutamine is effective, yet in terms of availability and cost, there are some limitations to its widespread use for OM treatment. Recombinant human keratinocyte growth factor has also been shown to be effective in reducing severe OM (27), but it has been reported to cause several adverse effects and its high cost renders it inaccessible to most patients. In the present study, we hypothesized that oral glutamine decreased mucositis severity due to its multiple properties that affect the mucositis healing process.

A major finding of the present study was that glutamine considerably decreased the incidence of grade 4 mucositis, which is the most aggressive form of mucositis often resulting in unavoidable therapy interruption. Treatment delay caused by mucositis was observed in 0 patients in group $\mathrm{G}$ and in $15 \%$ patients in group P. During the 6-week CRT regimen, weeks 5 and 6 were the most debilitating, during which patients continuously consumed opioid analgesics with NSAIDs and received parenteral or enteral nutrition through a nasogastric tube or gastric fistula due to feeding difficulties caused by severe pain. Glutamine significantly decreased the mean maximal mucositis grade at weeks 5 and 6 as well as NRS scores at weeks 4 , 5 and 6. Furthermore, physician-assessed mucositis correlated with NRS score and the duration of supplemental nutrition and opioid use was significantly lower in group $G$ than in group P.

Several studies tested whether glutamine decreased the incidence and severity of CRT-induced OM in bone marrow transplant (BMT) and hematopoietic cell transplant (HCT) populations $(14,28-34)$; some of these clinical trials, however, did not show a convincing benefit of glutamine from the perspective of decreasing OM incidence and severity $(14,34)$. These studies could not perform conclusive evaluations of the effects of glutamine in the prevention and treatment of OM due to the small sample size, inadequate design and suboptimal glutamine doses $(14,15,35)$. Further study is required to determine the effectiveness of oral glutamine supplementation in BMT and HCT patients. In terms of severity and location of mucositis, the differences between OM induced by local irradiation in HNC patients and that induced by systemic irradiation in BMT or HCT patients should be considered. During radiotherapy for $\mathrm{HNC}$, a large quantity of radiation is more likely to act directly on tumor cells in the head and neck area, and although the damage is localized, it is more severe in these patients.

The aim of this double-blind, randomized, placebocontrolled trial was to determine whether oral glutamine decreased the severity of mucositis in HNC patients. To our knowledge, this is the first well-designed randomized controlled trial in this field. Untreated newly diagnosed HNC patients were enrolled and treated with identical CRT regimens. Physicians well-versed in mucositis improved reliability of the data. Nurses were responsible for distributing each dose to patients, and a pharmacist managed patient compliance, which was $99.6 \%$. Poor nutritional status is expected to interfere with mucosal healing and regeneration by decreasing infiltration by immunocompetent cells (36). An independent NST, which was indispensable in the present study, evaluated patient nutritional status and the requirement for enteral feeding in both groups throughout treatment. The enteral nutrition administered in this study did not contain glutamine.

There were no significant differences between groups in weight loss, BMI and biochemical parameters such as albumin, transthyretin, transferrin, retinol-binding protein, iron, copper, zinc and amino acids throughout this study. Nutritional management by the NST maximized the non-nutritional effects of glutamine and enhanced the quality of the present study. In addition, there are several previous studies on mucositis, but each study evaluated mucositis induced by a variety of chemotherapeutic agents and the regimen was not unified. The incidence and severity of mucositis must be altered by chemotherapeutic agents which were actually used. In the present study, all patients were treated the completely same CRT regimen, and when the regimen had been changed, the patients were excluded in the statistical analysis. Our results should be considered reliable since all patients in both groups had the same opportunity to develop clinically significant mucositis; consequently, any differences in treatment outcome must be the result of glutamine supplementation.

There were no adverse events associated with glutamine intake, such as constipation, dry mouth or nausea. The clinical data did not show any differences in serum ammonia levels and amino acid profiles between groups. Notably, glutamine did not interfere with the therapeutic effects of CRT. The present study demonstrated that glutamine can be used safely in combination with CRT.

Mucositis, also known as mucosal barrier injury, is a biologically complex process involving several phases (37). Initially, mucosal injury is induced by oxidative stress and reactive oxygen species (ROS) generated by radiation and cisplatin. Glutamine is a precursor of glutathione, a major intracellular antioxidant protecting cells against oxidative stress. Exogenous glutamine administration restores tissue glutathione levels that are depleted after chemotherapy (22). We hypothesized that glutamine protected the mucosal epithelium from oxidative stress without a negative impact on tumor regression. Next, the ulcerative phase is associated most consistently with mucositis. This phase is symptomatic and carries a risk of bacterial translocation. There were no patients with grade 4 mucositis who presented with symptomatic bleeding from ulcers in this study. Glutamine reportedly suppresses ulcer formation (38). Finally, in the regeneration phase, it is necessary to have ample nitrogen supply for DNA synthesis and collagen for extracellular matrix formation. As a collagen precursor, hydroxyproline, which is indispensable for wound healing, is synthesized from glutamate, which is derived from glutamine.

In conclusion, the present study demonstrated that glutamine significantly decreases the severity of CRT-induced mucositis in HNC cancer patients. An integrative and multidisciplinary approach can result in substantial advances in the outcome of cancer therapy and improvement in patient quality of life. 


\section{Acknowledgements}

The authors thank the nursing staff of the Department of Otorhinolaryngology and the NST members of Osaka University Hospital. We also thank Dr Yutaka Niihara of Emmaus Medical, Inc., who provided glutamine, and the Matsutani Chemical Industry Co., Inc., that provided placebo.

\section{References}

1. Forastiere AA and Trotti A: Radiotherapy and concurrent chemotherapy: a strategy that improves locoregional control and survival in oropharyngeal cancer. J Nat Cancer Inst 91: 2065-2066, 1999.

2. Groome PA, O'Sullivan B, Mackillop WJ, Jackson LD, Schulze K, Irish JC, et al: Compromised local control due to treatment interruptions and late treatment breaks in early glottis cancer: population-based outcomes study supporting need for intensified treatment schedules. Int J Radiat Oncol Biol Phys 64: 1002-1012, 2006.

3. Rosenthal DI and Trotti A: Strategies for managing radiationinduced mucositis in head and neck cancer. Semin Radiat Oncol 19: 29-34, 2009.

4. Keefe DM, Schubert MM, Elting LS, Sonis ST, Epstein JB, Raber-Durlacher JE, et al: Updated clinical practice guidelines for the prevention and treatment of mucositis. Cancer 109: 820-831, 2007

5. Quinn B, Potting CM, Stone R, Blijlevens NM, Fliedner M, Margulies A and Sharp L: Guideline for the assessment of oral mucositis in adult chemotherapy, radiotherapy and haematopoetic stem cell transplant patients. Eur J Cancer 44: 61-72, 2008.

6. Cetinbas F, Yelken B and Gulbas Z: Role of glutamine administration on cellular immunity after total parenteral nutrition enriched with glutamine in patients with systemic inflammatory response syndrome. J Crit Care 25: 661.e1-661.e6, 2010.

7. Duggan C, Gannon J and Walker WA: Protective nutrients and functional foods for the gastrointestinal tract. Am J Clin Nutr 75 789-808, 2002.

8. Reeds PJ and Burrin DG: Glutamine and the bowel. J Nutr 131 (Suppl 9): 2505S-2508S, 2001.

9. Alpers DH: Glutamine: do the data support the cause for glutamine supplementation in humans? Gastroenterology 130 (Suppl 1): S106-S116, 2006.

10. Lacey JM and Wilmore DW: Is glutamine a conditionally essential amino acid? Nutr Rev 48: 297-309, 1990.

11. Savarese DM, Savy G, Vahdat L, Wischmeyer PE and Corey B: Prevention of chemotherapy and radiation toxicity with glutamine. Cancer Treat Rev 29: 501-513, 2003.

12. Huang EY, Leung SW, Wang CJ, Chen HC, Sun LM, Fang FM, et al: Oral glutamine to alleviate radiation-induced oral mucositis: a pilot randomized trial. Int J Radiat Oncol Biol Phys 46: 535-539, 2000.

13. Skubitz KM and Anderson PM: Oral glutamine to prevent chemotherapy induced stomatitis: a pilot study. J Lab Clin Med 127: 223-228, 1996.

14. Jebb SA, Marcus R and Elia M: A pilot study of oral glutamine supplementation in patients receiving bone marrow transplants. Clin Nutr 14: 162-165, 1995.

15. van Zaanen $\mathrm{HC1}$, van der Lelie $\mathrm{H}$, Timmer JG, Fürst $\mathrm{P}$ and Sauerwein HP: Parenteral glutamine dipeptide supplementation does not ameliorate chemotherapy-induced toxicity. Cancer 74: 2879-2884, 1994.

16. Jebb SA, Osborne RJ, Maughan TS, Mohideen N, Mack P, Mort D, et al: 5-fluorouracil and folinic acid-induced mucositis: no effect of oral glutamine supplementation. Br J Cancer 70: 732-735, 1994.

17. Anderson PM, Schroeder G and Skubitz KM: Oral glutamine reduces the duration and severity of stomatitis after cytotoxic cancer chemotherapy. Cancer 83: 1433-1439, 1998.

18. Smith RJ: Glutamine metabolism and its physiologic importance. JPEN J Parenter Enteral Nutr 14 (Suppl 4): 40S-44S, 1990.

19. Bellon G, Monboisse JC, Randoux A and Borel JP: Effects on preformed proline and proline amino acid precursors (including glutamine) on collagen synthesis in human fibroblast cultures. Biochim Biophys Acta 930: 39-47, 1987.
20. Bellon G, Chaqour B, Wegrowski Y, Monboisse JC and Borel JP: Glutamine increases collagen gene transcription in cultured human fibroblasts. Biochem Biophys Acta 1268: 311-323, 1995.

21. Alverdy JA, Aoys E, Weiss-Carrington P, Burke DA: The effect of glutamine-enriched TPN on gut immune cellularity. J Surg Res 52: 34-38, 1992.

22. Leitao RF, Ribeiro RA, Lira AM, Silva LR, Bellaguarda EA, Macedo FD, et al: Glutamine and alanyl-glutamine accelerate the recovery from 5-fluorouracil-induced experimental oral mucositis in hamster. Cancer Chemother Pharmacol 61: 215-222, 2008.

23. Nose S, Wasa M, Tazuke Y, Owari M and Fukuzawa M: Cisplatin upregulates glutamine transport in human intestinal epithelial cells: the protective mechanism of glutamine on intestinal mucosa after chemotherapy. JPEN J Parenter Enteral Nutr 34: 530-537, 2010.

24. Topkan E, Yavuz MN, Onal C and Yavuz AA: Prevention of acute radiation-induced esophagitis with glutamine in non-small cell lung cancer patients treated with radiotherapy: evaluation of clinical and dosimetric parameters. Lung Cancer 63: 393-399, 2009.

25. Cerchietti LC, Navigante AH, Lutteral MA, Castro MA, Kirchuk R, Bonomi M, et al: Double-blinded, placebo-controlled trial on intravenous L-alanyl-L-glutamine in the incidence of oral mucositis following chemoradiotherapy in patients with headand-neck cancer. Int J Radiat Oncol Biol Phys 65: 1330-1337, 2006.

26. Daniele B, Perrone F, Gallo C, Pignata S, De Martino S, De Vivo R, et al: Oral glutamine in the prevention of fluorouracil induced intestinal toxicity: a double blind, placebo controlled, randomized trial. Gut 48: 28-33, 2001.

27. Le QT, Kim H, Schneider CJ, Muraközy G, Skladowski K, Reinisch S, et al: Palifermin reduces severe mucositis in definitive chemoradiotherapy of locally advanced head and neck cancer: a randomized, placebo-controlled study. J Clin Oncol 29: 2808-2814, 2011

28. Aquino VM, Harvey AR, Garvin JH, Godder KT, Nieder ML, Adams RH, et al: A double-blind randomized placebo-controlled study of oral glutamine in the prevention of mucositis in children undergoing hematopoietic stem cell transplantation: a pediatric blood and marrow transplant consortium study. Bone Marrow Transplant 36: 611-616, 2005.

29. Blijevens NM, Donnelly JP, Naber AH, Schattenberg AV and DePauw BE: A randomized, double-blinded, placebo-controlled, pilot study of parenteral glutamine for allogeneic stem cell transplant patients. Support Care Cancer 13: 790-796, 2005.

30. Piccirillo N, De Matteis S, Sorà F, Laurenti L, Chiusolo P, Leone G and Sica S: Glutamine parenteral supplementation in stem cell transplant. Bone Marrow Transplant 33: 455, 2004.

31. Sykorova A, Horacek J, Zak P, Kmonicek M, Bukac J and Maly J: A randomized double blind comparative study of prophylactic parenteral nutritional support with or without glutamine in autologous stem cell transplantation for hematological malignancies - three years' follow-up. Neoplasm 52: 476-482, 2005.

32. Ziegler TR, Young LS, Benfell K, Scheltinga M, Hortos K, Bye R, et al: Clinical and metabolic efficacy of glutamine-supplemented parenteral nutrition after bone marrow transplantation: a randomized double-blind, controlled study. Ann Intern Med 116: 821-828, 1992

33. Young LS, Bye R, Scheltinga M, Ziegler TR, Jacobs DO and Wilmore DW: Patients receiving glutamine-supplemented intravenous feedings report an improvement in mood. JPEN J Parenter Enteral Nutr 17: 422-427, 1993.

34. Schloerb PR and Amare M: Total parenteral nutrition with glutamine in bone marrow transplantation and other clinical applications (a randomized, double-blind study). JPEN J Pareter Enteral Nutr 17: 407-413, 1993.

35. Coghlin Dickson TM, Womg RM, Offrin RS, Shizuru JA, Johnston LJ, Hu WW, et al: Effect of oral glutamine supplementation during bone marrow transplantation. JPEN J Parenter Enteral Nutr 24: 61-66, 2002

36. Curi R, Lagranha CJ, Doi SQ, Sellitti DF, Procopio J, PithonCuri TC, et al: Molecular mechanisms of glutamine action. J Cell Physiol 204: 392-401, 2005.

37. Sonis ST, Elting LS, Keefe D, Peterson DE, Schubert M, HauerJensen M, et al: Perspectives on cancer therapy-induced mucosal injury: pathogenesis, measurement, epidemiology, and consequences for patients. Cancer 100 (Suppl 9): S1995-S2025, 2004.

38. Okabe S, Takeuchi K, Nakamura K and Takagi K: Inhibitory effect of L-glutamine on the aspirin-induced gastric lesions in the rat. Pharm Pharmacol 26: 605-611, 1974. 